\title{
ELABORAÇÃO DE CALENDÁRIO AGRÍCOLA PARA A SEGUNDA SAFRA DE VERÃO (SAFRINHA) NAS ÁREAS DE CHAPADAS DA MESORREGIÃO DO TRIÂNGULO MINEIRO / ALTO PARANAÍBA - (MG)
}

\author{
Samuel Alves Maciel ${ }^{(a)}$, Washington Luiz Assunção ${ }^{(b)}$ \\ (a) Instituto de Geografia, Universidade Federal de Uberlândia, samuelgeo_alves@ufu.br \\ (b) Instituto de Geografia, Universidade Federal de Uberlândia, washington@ufu.br
}

\section{Eixo: Climatologia em difentes níveis escalares: mudanças e variabilidades}

\begin{abstract}
Resumo
O objetivo deste trabalho é analisar a duração da estação chuvosa de 1980 a 2013 e a partir desta elaborar um calendário agrícola da Segunda Safra de Verão (Safrinha) para as áreas de chapadas da mesorregião do Triângulo Mineiro / Alto Paranaíba - (MG). Foram utilizados dados de precipitação diária - $(\mathrm{mm})$ de 8 postos pluviométricos localizados na área de estudo, série histórica de 34 anos. Após a tabulação dos dados seguiram-se as etapas metodológicas do computo dos balanços hídricos, determinação da duração da estação seca e chuvosa e elaboração do calendário agrícola. A partir dos resultados inferiu-se que 54\% dos anos analisados em todos os postos apresentaram início da estação chuvosa entre o intervalo do $1^{\circ}$ ao $5^{\circ}$ quinquídio (dia 1 ao dia 25) de outubro. Período este, que foi orientado como o mais adequado para o início do plantio da soja e posterior safrinha (girassol, milho e sorgo).
\end{abstract}

Palavras chave: Estação Chuvosa, Segunda Safra de Verão, Calendário Agrícola.

\section{Introdução}

Apesar dos avanços tecnológicos relacionados ao maquinário, ao melhoramento genético de sementes e posterior produção, a agricultura ainda representa uma atividade dependente das condições climáticas para o seu bom desenvolvimento. Essencialmente em função do regime das chuvas, pois a distribuição de água equilibrada ao longo do ciclo fenológico das culturas garante uma ideal maturação fisiológica da planta, e, por fim, a realização de boas safras.

De acordo com Santos e Ribeiro (2004), uma vez que, as condições do tempo não são previsíveis, a agricultura pode ser referida como uma atividade de risco em recorrência de secas prolongadas, veranicos e chuvas excessivas. Tendo assim, a necessidade do envolvimento dos aspectos climáticos no planejamento agrícola.

Diversos trabalhos consideram a o estudo detalhado do ano hidrológico em suas pesquisas. "Desta forma, o conhecimento sobre a duração, quantidade e distribuição das chuvas, é fundamental para o planejamento 


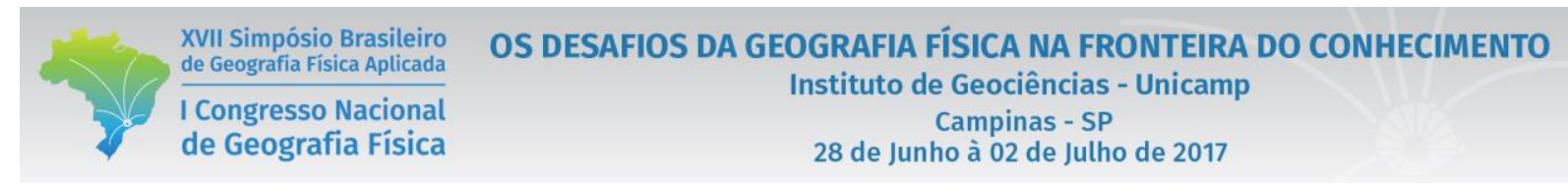

das atividades agrícolas e para as definições mais apropriadas ao preparo do solo e plantio." (CARVALHO et al.; 2000, p.173).

Segundo Abronsano (2012) o cultivo de safrinha em sucessão a cultura principal, pode ser uma boa alternativa ao agricultor por não trazer riscos diretos, devido ao fato de ser destinado como aumento de renda agrícola e não a formação da própria renda geral, que é de responsabilidade da cultura de verão. $\mathrm{O}$ mesmo autor ainda confirma em suas pesquisas a importância do clima para a prática da safrinha: "Nas avaliações de aptidão climática e fitotécnica das culturas oleaginosas, por exemplo, as condições térmicas e hídricas regionais são elementos imprescindíveis.” (ABRONSANO, 2012, p. 19).

Assim, a área de estudo deste trabalho compreende a mesorregião do Triângulo Mineiro / Alto Paranaíba, figura 1, situada na porção oeste do estado de Minas Gerais - (MG), entre as coordenadas geográficas de $17^{\circ} 55^{\prime} 12^{\prime \prime}$ e $20^{\circ} 41^{\prime} 30^{\prime \prime}$ de latitude sul e $45^{\circ} 33^{\prime} 30^{\prime \prime}$ e $51^{\circ} 02^{\prime} 18^{\prime \prime}$ de longitude oeste, ocupando uma área de $90.545 \mathrm{~km}^{2}$, o que equivale a $15,4 \%$ do território mineiro Segundo dados do Instituto Brasileiro de Geografia e Estatística (IBGE, 2010) a mesorregião possui um contingente populacional de 2.144.482 habitantes e é uma das doze mesorregiões que compõe MG.

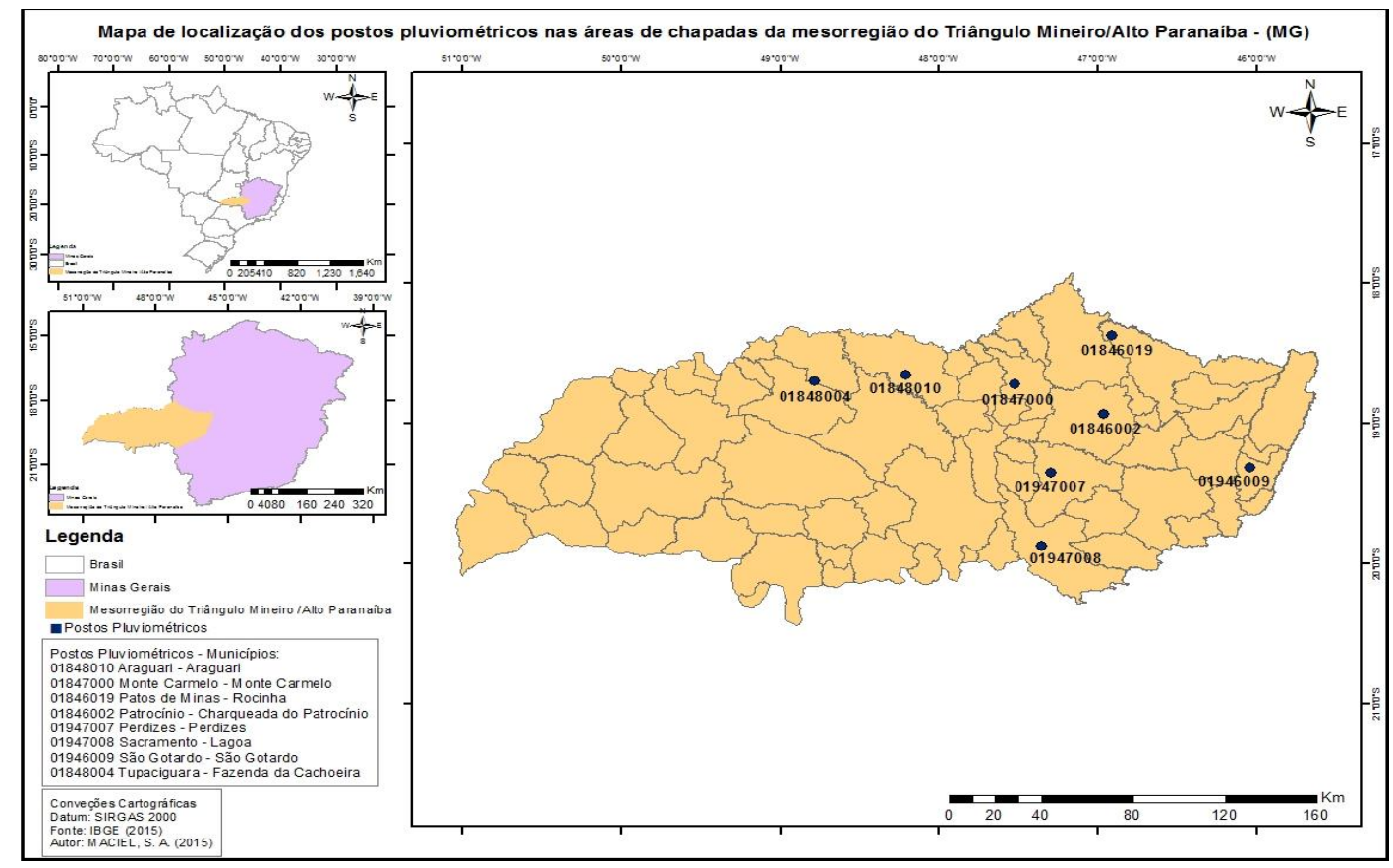

Figura 1 - Mapa de localização da mesorregião do Triângulo Mineiro / Alto Paranaíba - (MG) e do posicionamento das estações pluviométricas.

Fonte dos dados: IBGE (2015). Organização: MACIEL, S. A. (2015). 


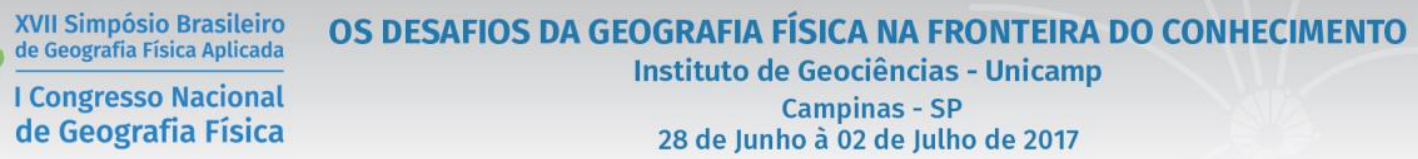

De acordo com os pressupostos e a relevância da temática abordada, este estudo tem como objetivo analisar a duração da estação chuvosa, no período de 1980 a 2013, e com base nesta elaborar um calendário agrícola da Segunda Safra de Verão (Safrinha) para as áreas de chapadas da mesorregião do Triângulo Mineiro / Alto Paranaíba - (MG).

\section{Materiais e Métodos}

Para elaboração deste trabalho inicialmente foi construído um referencial teórico - conceitual acerca do tema estudado. Na fase de processamento foram utilizados dados de precipitação diária (mm), em 24 horas, de 8 estações pluviométricas localizadas ao longo das áreas de chapadas da mesorregião do Triângulo Mineiro / Alto Paranaíba - (MG), tabela I. Estes constituíram uma série histórica de 34 anos, de 1980 a 2013. Os dados foram disponibilizados pelo Sistema de Informações Hidrológicas (HidroWeb) de responsabilidade da Agência Nacional de Águas (ANA).

Tabela I - Localização das estações pluviométricas da mesorregião do Triângulo Mineiro / Alto Paranaíba - (MG).

\begin{tabular}{ccccccc}
\hline $\mathbf{N}^{\circ}$ & $\begin{array}{c}\text { Código } \\
\text { do Posto }\end{array}$ & $\begin{array}{c}\text { Município de } \\
\text { Instalação }\end{array}$ & $\begin{array}{c}\text { Posto } \\
\text { Pluviométrico }\end{array}$ & $\begin{array}{c}\text { Latitude } \\
(\mathbf{S})\end{array}$ & $\begin{array}{c}\text { Longitude } \\
(\mathbf{W})\end{array}$ & $\begin{array}{c}\text { Altitude } \\
(\mathbf{m})\end{array}$ \\
\hline 1 & 01848010 & Araguari & Araguari & $18^{\circ} 39^{\prime} 04^{\prime \prime}$ & $48^{\circ} 12^{\prime} 33^{\prime \prime}$ & 956 \\
2 & 01847000 & Monte Carmelo & Monte Carmelo & $18^{\circ} 43^{\prime} 14 "$ & $47^{\circ} 31^{\prime \prime 2} 28^{\prime \prime}$ & 880 \\
3 & 01846019 & Patos de Minas & Rocinha & $18^{\circ} 22^{\prime} 25^{\prime \prime}$ & $46^{\circ} 54^{\prime} 54^{\prime \prime}$ & 898 \\
4 & 01846002 & Patrocínio & Charqueada do Patrocínio & $18^{\circ} 55^{\prime \prime} 48$ & $46^{\circ} 58^{\prime} 00^{\prime \prime}$ & 960 \\
5 & 01947007 & Perdizes & Perdizes & $19^{\circ} 20^{\prime} 55^{\prime \prime}$ & $47^{\prime} 17^{\prime} 43^{\prime \prime}$ & - \\
6 & 01947008 & Sacramento & Lagoa & $19^{\circ} 52^{\prime} 43^{\prime \prime}$ & $47^{\circ} 21^{\prime} 17^{\prime}$, & - \\
7 & 01946009 & São Gotardo & São Gotardo & $19^{\circ} 18^{\prime} 55^{\prime \prime}$ & $46^{\circ} 02^{\prime} 40^{\prime \prime}$ & - \\
8 & 01848004 & Tupaciguara & Fazenda da Cachoeira & $18^{\circ} 41^{\prime} 54^{\prime \prime}$ & $48^{\circ} 46^{\prime} 55^{\prime}$, & 793 \\
\hline
\end{tabular}

Fonte: HIDROWEB/ANA (2014). Organização: MACIEL, S. A. (2015).

O tratamento dos dados pluviométricos foi realizado com auxílio do software Sistema de Informações Hidrológicas Versão 1.2 (Hidro1.2) disponibilizado pela Superintendência de Gestão da Rede Hidrometeorológica e pela Agência Nacional das Águas (ANA) e posteriormente em planilha do programa Microsoft Office Excel 2007, afim de totalizar as somas diárias e mensais das chuvas.

Para a demarcação do início e término da estação chuvosa faz-se necessário o cálculo dos balanços hídricos climatológicos, afim da obtenção dos dados de evapotranspiração (ETP) mensais. Em tal finalidade, optou-se pelo modelo proposto por Thornthwaite e Matter (1995), com capacidade de armazenamento (CAD) $100 \mathrm{~mm}$, valor padrão utilizado, que também leva em consideração os valores de temperatura e precipitação, bem como a latitude e cada período do ano recorrente abordado. 


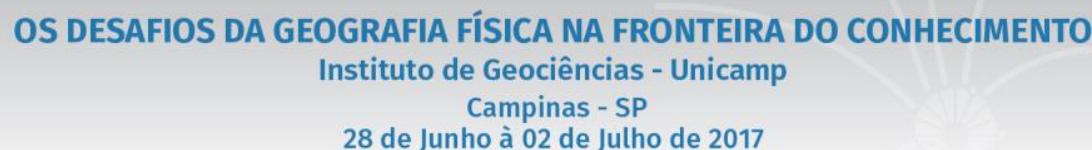

28 de Junho à 02 de Julho de 2017

A estimativa dos dados de temperatura foi realizada a partir dos cálculos que envolvem a equação de regressão linear múltipla, devido a falta de estações meteorológicas suficientes na área de estudo. O procedimento para utilização de tais dados foi desenvolvido por Novais e Assunção (2010) que baseados nesse tipo de equação, conjugam a temperatura com os valores de altitude, latitude e longitude, sendo que a primeira é a variável dependente e as posteriores as variáveis independentes.

Na obtenção dos valores finais do balanço hídrico utilizou-se o software elaborado por Rolim e Sentelhas (1998), da Escola Superior de Agricultura Queiroz, da Universidade de São Paulo (ESALQ/USP), através de uma planilha do software Microsoft Excel. Após a determinação dos valores de entrada da quantidade de umidade armazenada no solo para cada localidade e dos índices de evapotranspiração diária (ETP) encontrados, iniciou-se o procedimento de contagem do início e término da estação chuvosa de cada localidade da área de estudo.

Com vistas a definição da estação chuvosa priorizou-se uma análise mais detalhada da pluviosidade diária, para que fosse possível definir se existe ou não um padrão de duração das estações, e qual é este padrão. Desta maneira, diversos estudos produzidos por Assunção e D’Almeida (2004); Assunção (2008); Oliveira e Assunção (2010) e Santos e Assunção (2011) recorreram a esta temática e definiram que nas respectivas análises deve-se levar em consideração a distribuição diária das precipitações ao longo do período de estudo. Assunção (2013) irá, portanto, estabelecer de forma didática e de acordo com suas pesquisas anteriores, determinadas "Leis" básicas para a determinação da duração das estações secas e chuvosas na região do Brasil Central dominada pelos cerrados. Tais regras foram utilizadas para o desenvolvimento deste trabalho e estão sumariadas a seguir:

a) "Período chuvoso significa o fim do incremento do déficit hídrico no solo, o qual passa a ser reabastecido pelos excedentes hídricos (chuvas maiores que a ETP) e à medida que os dias vão passando, o nível de água acumulado no solo atinge a capacidade de campo e a partir de então começa o registro de excedentes hídricos, importantes na manutenção de um complexo sistema fluvial na região responsável pelo grande potencial hidroelétrico regional.

b) Os meses de dezembro, janeiro e fevereiro são todos considerados do período chuvoso. Quando houver o registro de déficit hídrico mensal este fato deve ser associado ao registro de um veranico (intervalo sem precipitações dentro da estação chuvosa) de média a forte intensidade.

c) Os meses de junho, julho e agosto são todos considerados do período seco. Caso ocorra o registro de excedentes hídricos em qualquer um desses meses este fato pode ser associado ao fenômeno conhecido localmente como "invernico" (ocorrência de chuvas mais intensas dentro da estação seca geralmente de origem frontal).

d) O período chuvoso tem início quando se verifica a ocorrência de uma chuva mais intensa (acima de $20 \mathrm{~mm}$ ) ou um acumulado de $40 \mathrm{~mm}$ em um curto período de dias (até 4 dias) e em seguida, as chuvas passam a ser mais frequentes e suficientes para repor a ETP acumulada e iniciar a reposição de água no solo.

e) Se houver chuvas bem distribuídas em setembro, não significa que este mês seja chuvoso. É preciso verificar se as precipitações em Outubro (se houve uma interrupção ou um período superior a 12 dias sem chuva) foram suficientes para repor a ETP do mês ou se houve déficit hídrico. 


\section{OS DESAFIOS DA GEOGRAFIA FÍSICA NA FRONTEIRA DO CONHECIMENTO \\ Instituto de Geociências - Unicamp \\ Campinas - SP \\ 28 de Junho à 02 de Julho de 2017}

f) Quando o mês de outubro apresentar-se úmido (com chuva igual ou superior a ETP mensal e bem distribuída) e em novembro verificar uma redução nos totais pluviométricos acumulados (porém superior a $60 \%$ da ETP mensal) a conclusão é de que a estação chuvosa teve seu início em outubro. Porém se observar nos primeiros dias de novembro uma grande sequiência de dias sem precipitações (acima de 12 dias), a estação chuvosa só começa após o reinício das chuvas depois desse período de interrupção.

g) O fim do período chuvoso (ou o início da estação seca) fica caracterizado após uma seqüência de 8 ou mais dias consecutivos sem ocorrência de precipitações ou com precipitações muito baixas nesse período e que nem atingem a metade da ETP diária. Após esse período as precipitações quando houver já não são tão frequentes e acima de tudo não são suficientes para repor os níveis de água no solo.

h) Se no mês de março ocorrer totais pluviométricos acumulados abaixo da ETP mensal e no mês de abril os acumulados ficarem acima de $80 \%$ da ETP mensal e com chuvas bem distribuídas ao longo do mês o que se observa e que as baixas precipitações em março devem-se a ocorrência do fenômeno veranico.

i) O mês de maio só é considerado úmido se em abril as chuvas foram abundantes e suficientes para repor a ETP mensal. Caso isso não ocorra, as chuvas mesmo abundantes no mês de maio passam a ser consideradas como chuvas isoladas.

j) Para efeito de análise considerou-se o início da estação seca no dia imediatamente após a última chuva antes de uma seqüência de 8 ou mais dias sem registro de chuvas ou com precipitações insignificantes (cujos acumulados diários geralmente fica abaixo da metade da ETP). Vale lembrar que como o solo está com o nível de água elevada os efeitos da estação seca como o "murchamento" e a cessão do crescimento vegetativa das culturas só se faz perceber após passar um período de alguns dias ( 8 a 10), sendo afetado em maior ou menor prazo em função da temperatura ambiente." (ASSUNÇÂO, 2013, p. 5 - 6).

Com a finalização dos quadros de duração da estação chuvosa dos municípios abordados neste trabalho, pode-se se ter parâmetros estabelecidos quanto ao início e ao término do período chuvoso para a construção dos calendários agrícolas propostos. A elaboração destes, para as culturas do milho, do girassol e do sorgo, foi realizada a partir do período de semeadura e colheita da cultura de primeira safra utilizada, neste caso a soja superprecoce. Já quanto às culturas de safrinhas para suas posteriores análises, também se levou em consideração este intervalo de semeadura a colheita, juntamente com a duração total do ciclo das culturas situado entre a semeadura e a maturação fisiológica, fase fenológica esta, em que a planta finaliza o processo de senescência e ocorre o encerramento da absorção de água pelas raízes.

Por fim, a tabela II apresenta a síntese do número de dias referente a cada período situado (semeadura a colheita e semeadura a maturação fisiológica) dentro de cada ciclo fenológico das culturas trabalhadas. Nesta, verifica-se que a soja superprecoce possui um total de 100 dias demarcados entre sua semeadura e a sua colheita. Como primeira cultura, ela é cultivada antes para posterior produção das segundas safras de verão (milho, girassol e sorgo) que apresentam, respectivamente, 80, 70 e 70 dias de duração entre a sua semeadura e a sua maturação fisiológica. Dentre essas culturas de "safrinha", o milho é o cultivar mais utilizado neste tipo de produção, e, enquanto as outras duas, o girassol e o sorgo por apresentarem a mesma quantidade de dias, entre a semeadura e a maturação fisiológica, ficarão a cargo do agricultor a sua escolha como a melhor cultura para a realização Segunda Safra de Verão.

Tabela II: Duração total de dias dos períodos situados dentro de cada ciclo fenológico das culturas: semeadura a colheita e semeadura a maturação fisiológica. 


\begin{tabular}{|c|c|c|}
\hline \multirow{2}{*}{$\begin{array}{l}\text { XVII Simpósio Brasileiro } \\
\text { de Geografia Fisica Aplicada } \\
\text { I Congresso Nacional } \\
\text { de Geografia Física }\end{array}$} & \multirow{2}{*}{\multicolumn{2}{|c|}{$\begin{array}{l}\text { OS DESAFIOS DA GEOGRAFIA FÍSICA NA FRONTEIRA DO CONHECIMENTO } \\
\text { Instituto de Geociências - Unicamp } \\
\text { Campinas - SP } \\
28 \text { de Junho à } 02 \text { de Julho de } 2017\end{array}$}} \\
\hline & & \\
\hline \multicolumn{3}{|c|}{ Duração total de dias para cada fase do ciclo fenológico } \\
\hline Cultura & Semeadura a Colheita & Semeadura a Maturação Fisiológica \\
\hline Soja Superprecoce & 100 & - \\
\hline Milho & 120 & 80 \\
\hline Girassol & 130 & 70 \\
\hline Sorgo & 100 & 70 \\
\hline
\end{tabular}

Fonte: MAPA (2014); EMBRAPA (1997); SILVA, M. L. (2011). Org.: MACIEL, S. A. (2015).

\section{Resultados}

A análise do climograma disposto na figura 2 demonstra que os meses de junho e julho são os que ocorrem as menores temperaturas mensais de $\left(18,7{ }^{\circ} \mathrm{C}\right.$ e $\left.18,9{ }^{\circ} \mathrm{C}\right)$, já os menores valores de precipitação são apresentados nos meses de junho a agosto com valores de $(15,2 \mathrm{~mm}, 10,2 \mathrm{~mm}, 13,6 \mathrm{~mm}$ respectivamente). Em relação aos meses mais quentes, constata-se que os meses de outubro a março tiveram os maiores valores de temperaturas médias mensais $\left(23,1{ }^{\circ} \mathrm{C}, 22,8{ }^{\circ} \mathrm{C}, 22,6{ }^{\circ} \mathrm{C}, 22,8{ }^{\circ} \mathrm{C}, 23,0{ }^{\circ} \mathrm{C}\right.$ e $22,8^{\circ} \mathrm{C}$ ), com destaque para outubro e fevereiro que demarcaram as maiores médias. Enquanto que os meses de novembro a fevereiro são sinalizados como o período onde ocorrem os maiores volumes de precipitação de (203,3 mm, 299,1 mm, 294,7 mm e 200,2 mm).O clima da área de estudo, ainda apresenta uma média anual de temperatura de $21,5^{\circ} \mathrm{C}$ e um total pluviométrico médio anual de $1.514,1 \mathrm{~mm}$.

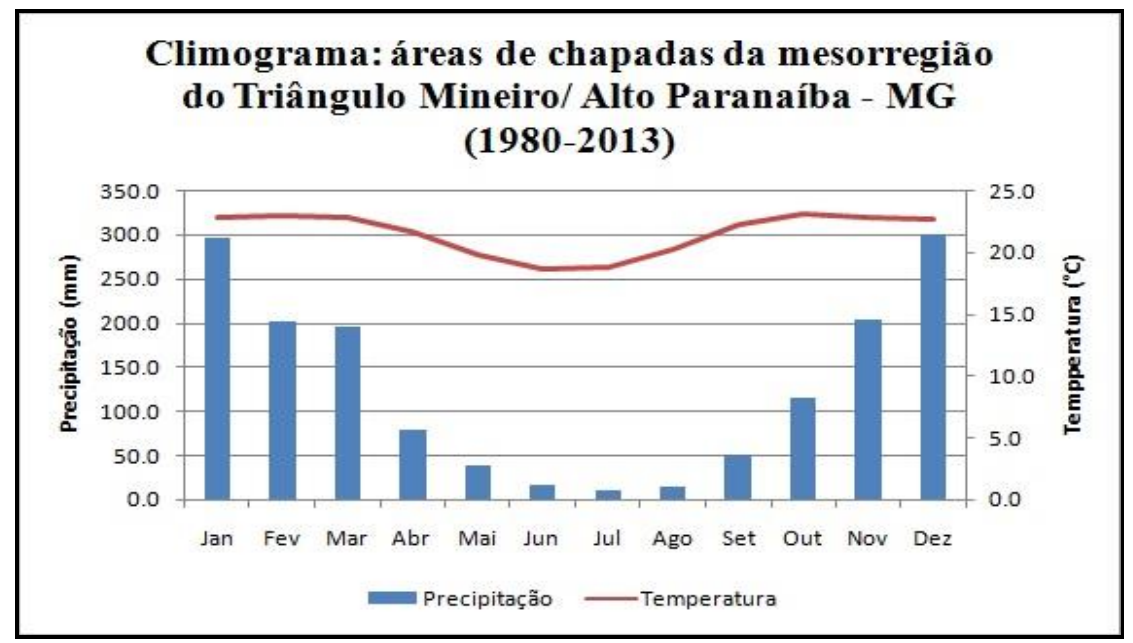

Figura 2: Climograma das áreas de chapadas da mesorregião do Triângulo Mineiro/ Alto Paranaíba - MG (19802013).

Fonte: HidroWeb/ANA (2014). Org.: MACIEL, S. A. (2015).

Portanto, caracterizam-se dois períodos bem definidos na área, quente e úmido de outubro a março e com temperaturas mais amenas e seco de abril a setembro. Sendo que, os meses de outubro a março, totalizados representam $86,3 \%$ ou $1.307,7 \mathrm{~mm}$ das chuvas anuais. A maior concentração de chuvas é 


\section{OS DESAFIOS DA GEOGRAFIA FÍSICA NA FRONTEIRA DO CONHECIMENTO \\ Instituto de Geociências - Unicamp \\ Campinas - SP \\ 28 de Junho à 02 de Julho de 2017}

delimitada entre o trimestre de dezembro a fevereiro, que somados respondem por $52,4 \%$ ou $794,0 \mathrm{~mm}$ do total anual. Enquanto que o trimestre mais seco, situado entre junho a agosto juntos, totalizam apenas 2,5\% ou 39,0 mm das chuvas anuais. Quadro físico este, de duas estações bem demarcadas, de valia para o cultivo da Segunda Safra de Verão (girassol, milho e sorgo), enquanto seu período ideal de plantio e colheita, evitando possíveis prejuízos quanto à produtividade agrícola. Entretanto, para elaboração do calendário agrícola, mesmo com as estações climáticas bem demarcadas, se faz necessário delimitar bem seu início e seu término, sobretudo, da estação chuvosa.

A título de exemplo, o quadro a seguir da figura 3 apresenta a duração da estação chuvosa em Monte Carmelo - (MG). Neste constatou-se que a estação chuvosa apresentou uma média de 174 dias de duração anual, tendo como os anos mais expressivos de variação interanual (1989/90; 2000/01) com 151 dias delimitados de duração e (1991/92) com 210 dias sinalizados para o período total da estação chuvosa. Entre os anos analisados verifica-se que a maioria dos anos hidrológicos teve o início da estação chuvosa no mês de outubro, totalizando $69 \%$ dos anos analisados, especificamente alternando entre $2^{\circ}$ e $6^{\circ}$ quinquídio (de 6 ao $10^{\circ}$ dia e de 26 a 31 dia). Já o intervalo de ano entre 1991/92 e 1992/93, apresentou a antecipação da estação chuvosa para o mês de setembro, a partir do $6^{\circ}$ quinquídio, enquanto que $24 \%$ de todos os anos apresentaram um início da estação chuvosa tardia, no começo do mês de novembro (1980/81, 1982/83, 1985/86, 1993/94, 2000/01, 2001/02, 2003/05 e 2008/09). Quanto ao seu término, a estação chuvosa se encerrou em grande parte no mês de abril, totalizando 93\%, principalmente a partir do $3^{\circ}$ quinquídio (de 11 ao $15^{\circ}$ dia). O mais tardio do fim da estão chuvosa neste caso, esteve entre os anos de 1982/83, 1985/86 e 1990/91, que se encerram a partir do dia 26 de abril com limite para o fim do mesmo mês. 
XVII Simpósio Brasileiro de Geografia Fisica Aplicada

I Congresso Nacional de Geografia Física
OS DESAFIOS DA GEOGRAFIA FÍSICA NA FRONTEIRA DO CONHECIMENTO

Instituto de Geociências - Unicamp

Campinas - SP

28 de Junho à 02 de Julho de 2017

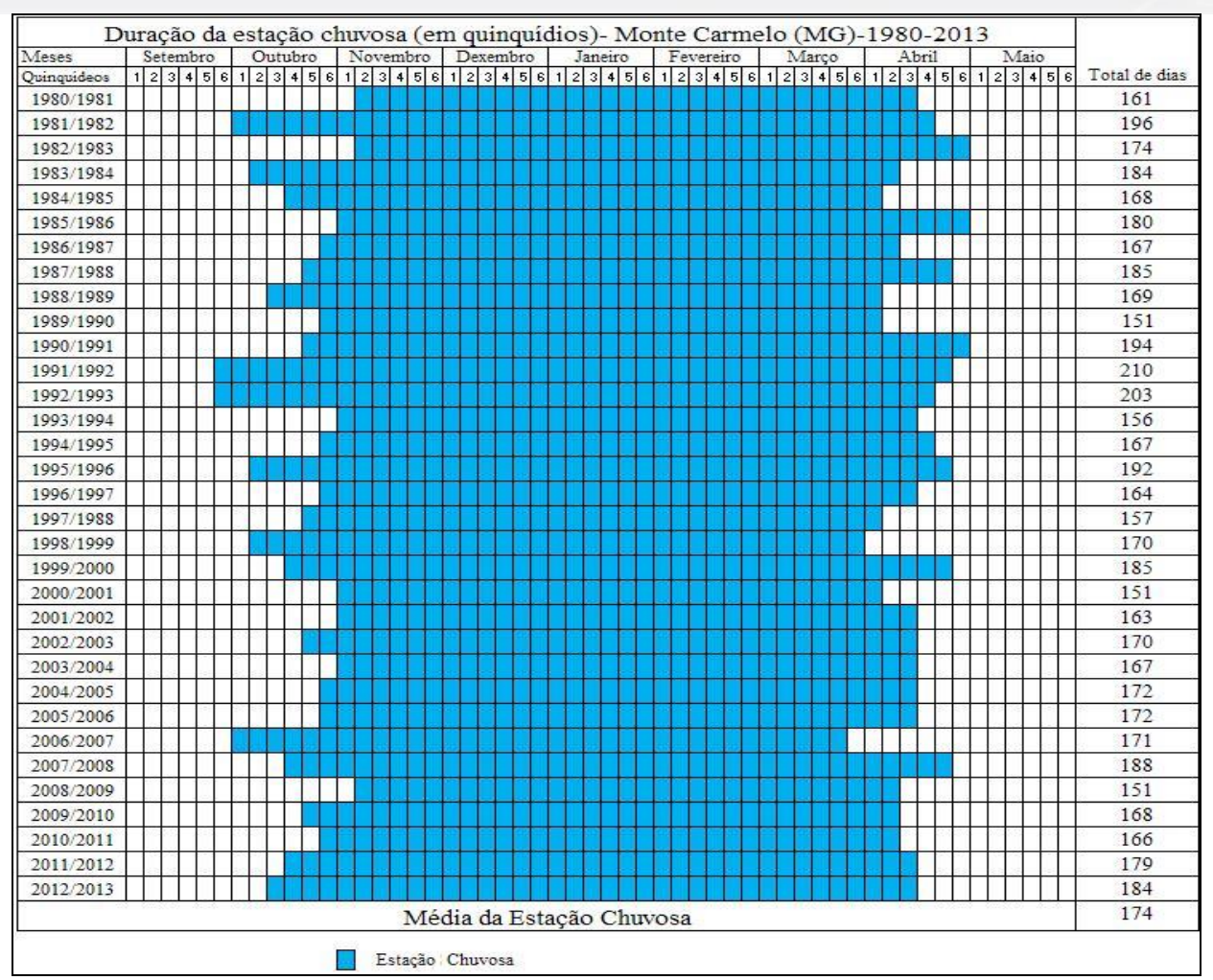

Figura 3: Duração da estação chuvosa de Monte Carmelo - MG: (1980-2013).

Fonte: HidroWeb/ANA (2014). Org.: MACIEL, S. A. (2015).

A partir da delimitação da estação chuvosa para as áreas de chapadas da mesorregião do Triângulo Mineiro / Alto Paranaíba - (MG) - pode-se encontrar as porcentagens para cada data de início e término da mesma, diante da série histórica de dados (1980-2013), ilustrado nos gráficos das figuras 4. Tais percentuais foram utilizados para elaboração dos calendários agrícolas propostos, uma vez que, adequouse estas datas ao número de dias necessários para o desenvolvimento da planta, o ciclo fenológico.

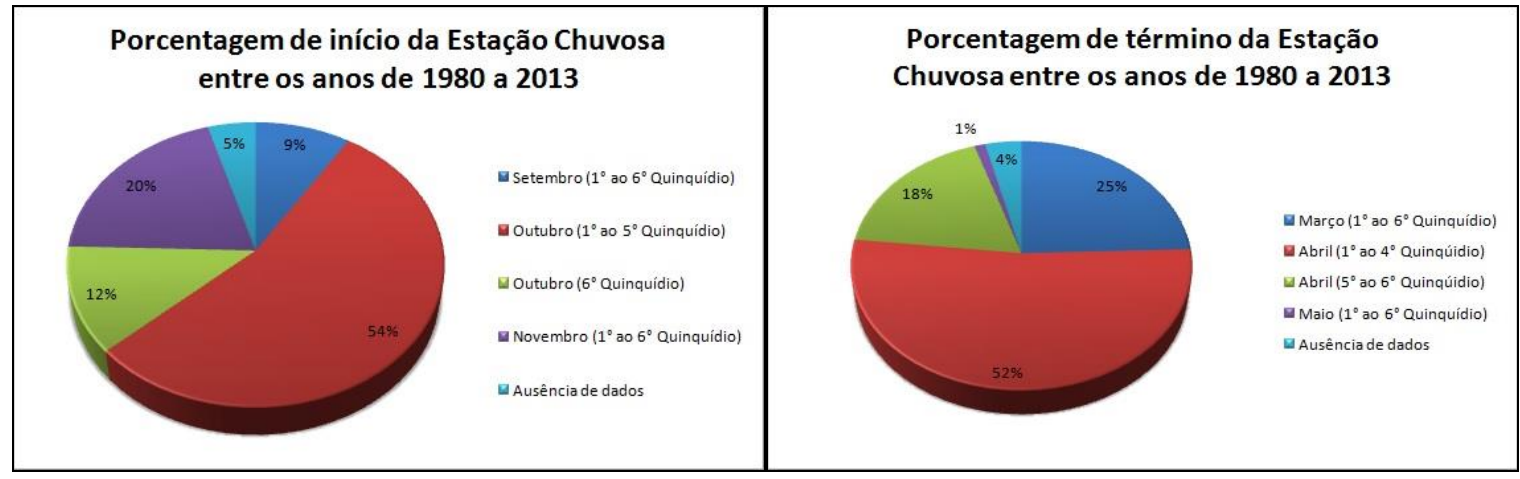

Figura 4: Porcentagem de início e término da Estação Chuvosa para as áreas de chapadas da mesorregião do Triângulo Mineiro/ Alto Paranaíba (MG), entre os anos de 1980 a 2013.

Fonte: HidroWeb/ANA (2014). Org.: MACIEL, S. A. (2015). 


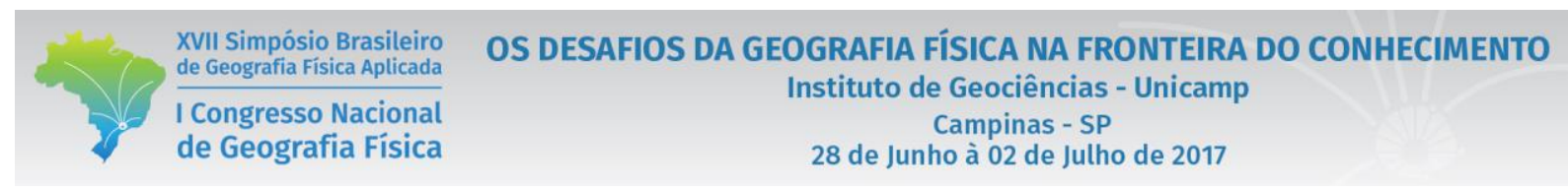

$\mathrm{Na}$ figura 4 constata-se que o maior percentual (54\%) de início da estação chuvosa esteve demarcado entre o intervalo de dias do $1^{\circ}$ ao $5^{\circ}$ quinquídio (dia 1 ao dia 25) de outubro. Período este, que foi orientado como o mais adequado para o início do plantio de soja e posterior safrinha, tendo em vista o número total de dias situado entre o plantio da primeira cultura e a maturação fisiológica da Segunda Safra e o período completo entre o plantio da primeira e a colheita desta segunda.

Como a maior porcentagem (52\%) de término da estação chuvosa na maioria das localidades esteve situada entre o $1^{\circ}$ e $4^{\circ}$ quinquídio (dia 1 ao dia 20) de abril, os calendários também foram planejados para que o seu início se adequasse a quantidade de dias chuvosos ocorridos até o fim da estação, nesta referida data. Uma vez que, para o mês de abril, entre o $5^{\circ}$ e $6^{\circ}$ quinquídio (dia 21 ao dia 30), a porcentagem de término da estação chuvosa foi baixa (18\%) quando comparada ao percentual total dos períodos de fim demarcados, também não se recomenda que o calendário agrícola seja proposto, com vistas para que o período de cultivo se encerre nesta mesma data. Pois, as quantidades de chuvas acumuladas já são escassas e insuficientes ao valor necessário de água para maturação fisiológica do cultivo.

Os quadros que se seguem dispostos na figura 5 e 6 apresentam os calendários agrícolas para o cultivo das culturas de Segunda Safra de Verão (girassol, milho e sorgo) nas áreas de chapadas da mesorregião do Triângulo Mineiro/ Alto Paranaíba (MG).

\begin{tabular}{|c|c|c|c|c|c|c|c|c|c|c|}
\hline Meses & Outubro & Novembro & Dexembro & Janeiro & Fevereiro & Março & Abril & Maio & Meses & Total de dias \\
\hline Culturas & \begin{tabular}{|l|l|l|l|l|l|}
1 & 2 & 3 & 4 & 5 & 6 \\
\end{tabular} & 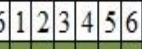 & \begin{tabular}{l|l|l|l|l|l|}
1 & 2 & 3 & 4 & 5 & 6 \\
\end{tabular} & 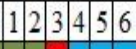 & \begin{tabular}{l|l|l|l|l|l|}
1 & 2 & 3 & 4 & 5 & 6 \\
\end{tabular} & 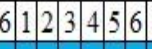 & \begin{tabular}{l|l|l|l|l|l|l}
1 & 2 & 3 & 4 & 5 & 6 & 1 \\
\end{tabular} & \begin{tabular}{l|l|l|l|l|l|}
1 & 2 & 3 & 4 & 5 & 6 \\
\end{tabular} & Culturas & \\
\hline Soja Superprecoce & & & & & & & & & Milho & 185 \\
\hline Soja Superprecoce & & & & & & & & & Milho & 225 \\
\hline \multirow[t]{3}{*}{ Legenda: } & \multicolumn{4}{|c|}{ Semeadura a colheita (Soja Superprecoce) } & \multicolumn{5}{|c|}{ Intervalo de tempo entre a colheita de Soja } & \\
\hline & \multicolumn{4}{|c|}{ Semeadura a maturação fisiológica (Milho) } & \multicolumn{5}{|c|}{ Superprecoce e a semadura de Milho } & \\
\hline & \multicolumn{4}{|c|}{ Semeadura a colheita (Milho) } & & & & & & \\
\hline Meses & Outubro & Novembro & Dexembro & Janeiro & Fevereiro & Março & Abril & Maio & \multirow{2}{*}{\begin{tabular}{|c|} 
Meses \\
Culturas \\
\end{tabular}} & \multirow{2}{*}{ Total de dias } \\
\hline Culturas & 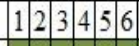 & \begin{tabular}{l|l|l|l|l|l|}
1 & 2 & 3 & 4 & 5 & 6 \\
\end{tabular} & 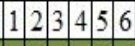 & \begin{tabular}{l|l|l|l|l|l|}
1 & 2 & 3 & 4 & 5 & 6 \\
\end{tabular} & 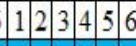 & 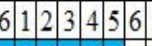 & \begin{tabular}{l|l|l|l|l|l|l}
1 & 2 & 3 & 4 & 5 & 6 & 1 \\
\end{tabular} & \multirow[t]{2}{*}{ 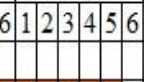 } & & \\
\hline Soja Superprecoce & & & & & & & & & Girassol & 175 \\
\hline Soja Superprecoce & & & & & & & & & Girassol & 235 \\
\hline \multirow[t]{3}{*}{ Legenda: } & \multicolumn{4}{|c|}{ Semeadura a colheita (Soja Superprecoce) } & \multicolumn{5}{|c|}{ Intervalo de tempo entre a colheita de Soja } & \\
\hline & \multirow{2}{*}{\multicolumn{4}{|c|}{$\begin{array}{l}\text { Semeadura a maturação fisiológica (Girassol) } \\
\text { Semeadura a colheita (Girassol) }\end{array}$}} & \multicolumn{5}{|c|}{ Superprecoce e a semadura de Girassol } & \\
\hline & & & & & & & & & & \\
\hline Meses & Outubro & Novembro & Dexembro & Janeiro & Fevereiro & Março & Abril & Maio & Meses & \multirow[t]{2}{*}{ Total de dias } \\
\hline Culturas & 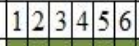 & 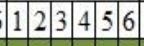 & 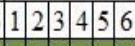 & 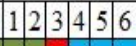 & \begin{tabular}{|l|l|l|l|l|l|}
1 & 2 & 3 & 4 & 5 & 6 \\
\end{tabular} & 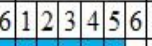 & \begin{tabular}{l|l|l|l|l|l|l}
1 & 2 & 3 & 4 & 5 & 6 & 1 \\
\end{tabular} & 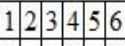 & Culturas & \\
\hline Soja Superprecoce & & & & & & & & & Sorgo & 175 \\
\hline Soja Superprecoce & & & & & & & & & Sorgo & 205 \\
\hline Legenda: & Semeadur & ra a colheita (S & Soja Superpre & ecoce) & Intervalo de & e tempo entre $a$ & a colheita de $S$ & Soja & & \\
\hline & Semeadur & ra a maturação & o fisiológica ( & Sorgo) & Superprecoc & ce e a semadur & ra de Sorgo & & & \\
\hline & Semeadur & a a colheita (S & Sorgo) & & & & & & & \\
\hline
\end{tabular}

Figura 5: Calendários Agrícolas para o milho, o girassol e o sorgo, a partir do $1^{\circ}$ quinquídio de outubro. Org.: MACIEL, S. A. (2015). 


\begin{tabular}{|c|c|c|c|c|c|c|c|c|c|c|}
\hline Meses & Outubro Novembro & Dexembro & Janeiro & Fevereiro & Março & Abril & Maio & Junho & Meses & Total de dias \\
\hline Culturas & 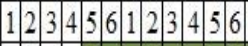 & \begin{tabular}{l|l|l|l|l|l|l|}
1 & 2 & 3 & 4 & 5 & 6 \\
\end{tabular} & 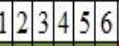 & 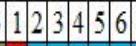 & \begin{tabular}{l|l|l|l|l|l}
1 & 2 & 3 & 4 & 5 & 6 \\
\end{tabular} & \begin{tabular}{l|l|l|l|l|l|l|}
1 & 2 & 3 & 4 & 5 & 6 \\
\end{tabular} & \begin{tabular}{|l|l|l|l|l|l|}
2 & 3 & 4 & 5 & 6 & \\
\end{tabular} & 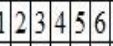 & Culturas & \\
\hline Soja Superprecoce & & & & & & & & & Milho & 185 \\
\hline Soja Superprecoce & & & & & & & & & Milho & 225 \\
\hline \multirow[t]{3}{*}{ Legenda: } & \multicolumn{3}{|c|}{ Semeadura a colheita (Soja Superprecoce) } & \multicolumn{6}{|c|}{ Intervalo de tempo entre a colheita de Soja } & \\
\hline & \multicolumn{3}{|c|}{ Semeadura a maturação fisiológica (Milho) } & \multicolumn{6}{|c|}{ Superprecoce e a semadura de Milho } & \\
\hline & \multicolumn{3}{|c|}{ Semeadura a colheita (Milho) } & & & & & & & \\
\hline Meses & Outubro Novembro & Dexembro & Janeiro & Fevereiro & Março & Abril & Maio & Junho & \multirow{2}{*}{\begin{tabular}{|l} 
Meses \\
Culturas
\end{tabular}} & \multirow{2}{*}{ Total de dias } \\
\hline Culturas & 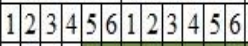 & \begin{tabular}{l|l|l|l|l|l|l|}
1 & 2 & 3 & 4 & 5 & 6 \\
\end{tabular} & \begin{tabular}{l|l|l|l|l|l|}
1 & 2 & 3 & 4 & 5 & 6 \\
\end{tabular} & 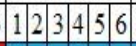 & 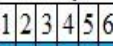 & 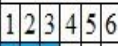 & \multirow{2}{*}{\multicolumn{2}{|c|}{ 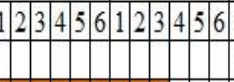 }} & & \\
\hline Soja Superprecoce & & & & & & & & & Girassol & 175 \\
\hline Soja Superprecoce & & & & & & & & & Girassol & 235 \\
\hline & & & & \multirow{2}{*}{\multicolumn{6}{|c|}{ Intervalo de tempo entre a colheita de Soja }} & \\
\hline \multirow[t]{3}{*}{ Legenda: } & \multicolumn{3}{|c|}{ Semeadura a colheita (Soja Superprecoce) } & & & & & & & \\
\hline & \multicolumn{3}{|c|}{ Semeadura a maturação fisiológica (Girassol) } & & \\
\hline & \multicolumn{3}{|c|}{ Semeadura a colheita (Girassol) } & \multicolumn{6}{|c|}{ Superprecoce e a semadura de Milho } & \\
\hline Meses & \begin{tabular}{l|l} 
Outubro & Novembro \\
\end{tabular} & Dexembro & Janeiro & Fevereiro & Março & Abril & Maio & Junho & Meses & Total de dias \\
\hline Culturas & 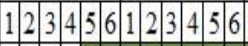 & \begin{tabular}{l|l|l|l|l|l|}
1 & 2 & 3 & 4 & 5 & 6 \\
\end{tabular} & \begin{tabular}{l|l|l|l|l|l|}
1 & 2 & 3 & 4 & 5 & 6 \\
\end{tabular} & \begin{tabular}{l|l|l|l|l}
1 & 2 & 3 & 4 & 5
\end{tabular} & \begin{tabular}{l|l|l|l|l|l}
1 & 2 & 3 & 4 & 5 & 6 \\
\end{tabular} & \begin{tabular}{|l|l|l|l|l|l|}
2 & 3 & 4 & 5 & 6 \\
\end{tabular} & \begin{tabular}{l|l|l|l|l|l|}
2 & 3 & 4 & 5 & 6 & 1 \\
\end{tabular} & 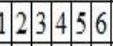 & Culturas & \\
\hline Soja Superprecoce & & & & & & & & & Sorgo & 175 \\
\hline Soja Superprecoce & & & & & & & & & Sorgo & 205 \\
\hline & & & & & & & & & & \\
\hline Legenda: & Semeadura a colheita (S & Soja Superprec & coce) & Intervalo de t & empo entre & a colheita de & Soja & & & \\
\hline & Semeadura a maturação & o fisiológica (S & iorgo) & Superprecoce & e a semadu & ra de Milho & & & & \\
\hline & Semeadura a colheita (S & Sorgo) & & & & & & & & \\
\hline
\end{tabular}

Figura 6: Calendários Agrícolas para o milho, o girassol e o sorgo, a partir do $5^{\circ}$ quinquídio de outubro. Org.: MACIEL, S. A. (2015).

Ao analisar os quadros de duração da estação chuvosa em cada município abordado neste trabalho, podese constatar que a média total do número de dias de todo o ciclo chuvoso está demarcada entre 169 a 178 dias. Estes em comparação com a totalidade de dias do período demarcado entre a semeadura da soja superprecoce e a maturação fisiológica do milho (185 dias), a semeadura da soja superprecoce e a maturação fisiológica do girassol (175 dias) e a semeadura da soja superprecoce e maturação fisiológica do sorgo (175 dias), demonstram a real viabilidade da produção de safrinha nas áreas de chapada da mesorregião. Pois, a duração total de dias da estação chuvosa apresenta praticamente a mesma quantidade de dias necessários para o desenvolvimento das plantas estudadas, ou seja, período este em que os cultivos necessitam de água para se nutrir, tendo como reflexo um bom crescimento e maturação fisiológica em sua produção.

A soja quando plantada no $1^{\circ}$ quinquídio (dia 1 ao dia 5) do mês de outubro terá seu ciclo de produção final com término no $2^{\circ}$ quinquídio (dia 6 ao dia 10) do mês de janeiro, o que já permitirá a semeadura do milho no próximo qüinquí́dio, no caso o $4^{\circ}$ (dia 16 ao dia 20) de janeiro. Pois é dado pelo agricultor um pequeno intervalo de 1 quinquídio (5 dias) entre a colheita da primeira cultura e o plantio da Segunda 
Safra. Tendo como data final de maturação fisiológica da planta, o $1^{\circ}$ quinquídio (dia 1 ao dia 5) do mês de abril, o que estaria demarcado ainda dentro da estação chuvosa para a região.

Já quando o plantio da soja ocorre no $5^{\circ}$ quinquídio (dia 21 ao dia 25) do mês de outubro, data limite demarcada neste trabalho como ideal para a produção de safrinha, terá seu ciclo fenológico final com término no $6^{\circ}$ quinquídio (dia 26 ao dia 31 ) de janeiro, tendo a semeadura do milho, por exemplo, no $2^{\circ}$ quinquídio (dia 6 ao dia 10) de fevereiro. A maturação fisiológica desta última cultura, por sua vez, ocorrerá no $5^{\circ}$ quinquídio (dia 21 ao dia 25 ) de abril.

O girassol, por sua vez, quando o plantio da soja também ocorreu no $5^{\circ}$ quinquídio (dia 21 ao dia 25) de outubro, teve sua maturação fisiológica concluída no $3^{\circ}$ (dia 11 ao dia 15) quinquídio de abril, sendo que o sorgo também teve sua maturação fisiológica finalizada na mesma data, o que também estaria dentro da estação chuvosa para a área de estudo, sobretudo, na maioria dos anos. Como a partir deste ponto a perda de água no solo e na planta é gradativa, caso não ocorra nenhum evento climático, a colheita certamente ocorrerá na data ideal a ser realizada.

Portanto, a data mais adequada para o inicio do calendário agrícola das safrinhas é durante o $1^{\circ}$ ao $5^{\circ}$ quinquídio (dia 1 ao dia 25) de outubro. Pois mesmo que ocorram alguns azares climáticos que sugiram riscos a produção e a produtividade final, como por exemplo, secas, geada, granizo e ou ventanias, a maturação fisiológica terá tempo hábil de ocorrer antes do final da estação chuvosa que ocorre principalmente entre o $1^{\circ}$ e $4^{\circ}$ quinquídio (dia 1 ao dia 20) do mês de abril.

\section{Considerações Finais}

Estudos como este são de crucial importância para o incremento da agricultura e melhoria da rentabilidade do produtor rural. A partir da metodologia utilizada para definir o início e término da estação chuvosa, foi possível verificar que as informações pluviométricas são de real importância para o planejamento agrícola. Devido ao fato, de subsidiar informações necessárias para escolha da cultura mais adequada para ser cultivada naquele momento, bem como diminuir os riscos de produtividade e de renda da atividade.

A duração da estação chuvosa nas áreas de chapadas da mesorregião do Triângulo Mineiro/ Alto Paranaíba - MG apresentou uma média de duração total de dias de 174, sendo que o município de Araguari apresentou o menor número com 169 dias e Tupaciguara o maior período com 178 dias. Quanto ao seu início, este ocorreu principalmente entre o $1^{\circ}$ e $5^{\circ}$ quinquídio de outubro (dia 1 ao dia 25), o que de fato orientou a proposta de elaboração dos calendários agrícolas no que se refere ao início de seu plantio da cultura de primeira safra, nesta mesma data.

Datas de plantio da soja, por exemplo, fora do período sugerido como ideal para o início da produção nos resultados desta pesquisa, ou seja, do $6^{\circ}$ quinquídio (dia 26 ao dia 31) de outubro a diante, poderão 
promover o insucesso das Safrinhas. Pois estas últimas culturas necessitariam de água até a sua maturação fisiológica que ocorreria já no fim da estação chuvosa, onde as chuvas já se tornam mais escassas e irregulares. Destaca-se que o término da estação chuvosa na mesorregião esteve mais presente entre o $1^{\circ} \mathrm{e}$ $4^{\circ}$ quinquídio (dia 1 ao dia 20 ) do mês de abril.

\section{Bibliografia}

AMBROSANO, Lucas. Avaliação de plantas oleaginosas potenciais para o cultivo de safrinha. 2012. 81 f. Dissertação (Mestrado) - Curso de Agronomia, Universidade Federal de Lavras, Lavras, 2012. Disponível em: <http://repositorio.ufla.br/bitstream/1/827/2/DISSERTAÇÃO. Avaliação de plantas oleaginosas potenciais para cultivo de safrinha.pdf>. Acesso em: 3 jul. 2014.

ASSUNÇÃO, Washington Luiz. Metodologia para definição da duração das estações seca e chuvosa na região dos cerrados do Brasil Central - Primeira Aproximação. In: ENCONTRO DE GEÓGRAFOS DA AMÉRICA LATINA, 14., 2013, Peru. Anais. Peru: Egal, 2013. p. 1 - 14.

CARVALHO, Daniel Fonseca de et al. Espacialização do período de veranico para diferentes níveis de perda de produção na cultura do milho, na bacia do Rio Verde Grande, MG. Revista Brasileira de Engenharia Agrícola e Ambiental, Campina Grande, v. 4, n. 2, 2000. Disponível em: $<$ http://www.scielo.br/scielo.php?script=sci_arttext\&pid=S1415-43662000000200007>. Acesso em: 21 jul. 2014.

EMBRAPA. Cultivo do milho. $1997 . \quad$ Disponível em: <http://www.cnpms.embrapa.br/publicacoes/milho_6_ed/manejomilho.htm>. Acesso em: 15 jul. 2014. HidroWeb - ANA. Dados Hidrológicos. Disponível em: <http://hidroweb.ana.gov.br/>. Acesso em: 17 mar. 2014.

IBGE. IBGE - CIDADES@.2010. Disponível em: <http://www.cidades.ibge.gov.br/xtras/home.php>. Acesso em: 4 ago. 2014.

NOVAIS, Giuliano Tostes. Caracterização Climática da Mesorregião do Triângulo Mineiro/Alto Paranaíba e do entorno da Serra da Canastra - MG. 2011. 175 f. Dissertação (Mestrado) - Curso de Geografia, Universidade Federal de Uberlândia, Uberlândia, 2011. Disponível em: <http://repositorio.ufu.br/bitstream/123456789/1195/1/CaracterizaçãoClimáticaMesorregião_parte 1.pdf>. Acesso em: 08 jul. 2014.

ROLIM, G. S.; SENTELHAS, P. C.; BARBIERI, V. Planilhas no ambiente EXCEL para os cálculos de balanços hídricos: normal, sequencial, de cultura e de produtividade real e potencial. Revista Brasileira de Agrometeorologia, Santa Maria, v.6, 1998, p.133-137.

SANTOS, Enio Rodovalho do; RIBEIRO, Antônio Giacomini. Clima e agricultura no município de Coromandel (MG). Caminhos da Geografia: revista on line, Uberlândia, v. 13, n. 5, p.122-140, 22 ago. 2004. Disponível em: <http://www.seer.ufu.br/index.php/caminhosdegeografia/article/view/15357/8656>. Acesso em: 15 mar. 2013.

SILVA, Michel Lopes. Avaliação de genótipos de sorgo forrageiro na zona da mata de Alagoas. 2011. 68 f. Tese (Doutorado) - Curso de Zootecnia, Centro de Ciências Agrárias, Universidade Federal de Alagoas, Rio Largo, 2011. Disponível em: <http://www.ufal.edu.br/unidadeacademica/ceca/posgraduacao/zootecnia/dissertacoes/michel-lopes-silva>. Acesso em: 3 fev. 2015.

THORNTHWAITE, C. W.; MATTER, J. R. The water balance. Publications in Climatology. New Jersey: Drexel Institute of Technology, 1955, 104p. 